\title{
RNA SYNTHETIC ACTIVITY IN THE MITOTIC NUCLEI
}

\author{
AKIO KUSANAGI \\ Radiobiology Division, Tokyo Metropolitan Institute for Radiological \\ Research, Fukazawa, Setagaya, Tokyo
}

Received July 24, 1964

Of particular interest to the biologists is that mitosis is found to be a depressed period of metabolic activity. The deoxyribonucleic acid (DNA) bound to mitotic chromosomes is known to depress the synthesis of DNA-dependent RNA, e.g., messenger RNA (Mazia and Prescott 1959; Konrad 1963). This hypothesis has been previously supported by several investigators in several cell types of both animals and plants (Taylor 1959; Woodard, Rasch and Swift 1961; Prescott and Bender 1962).

Luzula purpurea is known to have marked cytological characteristics such as low chromosome number, $\mathrm{n}=3$, large chromosome size, $8 \sim 10 \mu$, and lack of constriction (Malheiros, Castro and Camara 1947). The coiling cycle of mitotic chromosomes in this species can be traced in detail during the course of mitosis. These cytological characteristics are useful for testing the validity of the above hypothesis, i.e, whether the DNA packed in the mitotic chromosome depresses the activity of RNA metabolism or not.

The following experiment was undertaken to study a metabolic pattern of the RNA in chromosomes and nucleoli of meristematic cells in root tip of L. purpurea during the course of mitosis. The data obtained herein suggest that a drastic reduction in RNA synthesis observed in mitotic phases is very likely to be due to the coiled condition of the chromosomes.

\section{MATERIAL AND METHODS}

Root tip cells of the seedlings of Luzula purpurea $(n=3)$, usually at least 5 days after germination, were used in the present experiment. As a tracer tritiated uridine was used to incorporate into RNA. Roots of the seedlings were immersed in a nutrient solution containing uridine- $\mathrm{H}^{3}(2.5 \mu \mathrm{c} / \mathrm{ml})$ for 10 minutes. Fresh roots were collected immediately after treating with uridine $-\mathrm{H}^{3}$ and were smeared on the slide-glass and then fixed and gently squashed in acetic-alcohol solution $(1: 3)$. These slides were covered with Fuji ET-2 E stripping film after removal of the cover slip by dry-ice method (Conger and Fairchild 1953). All autoradiograms were stained with pyroninmethylgreen after photographic processing in usual ways. At least 20 cells in each mitotic phase were scored for each slide. 
In order to confirm whether radioactivity of chromosomes and nucleoli is of labeled RNA origin or not, autoradiographs of labeled nuclei were photographed and the preparation was treated with $5 \%$ perchloric acid to remove the RNA for 24 hours at ca. $4^{\circ} \mathrm{C}$. Fresh stripping film was then applied and reexposed for the same period as the first exposure. It was observed that radioactivity of chromosomes and nucleoli is substantially reduced by the perchloric acid treatment.

\section{RESULTS AND DISCUSSION}

A drastic reduction of incorporation of uridine into chromosomes can clearly be seen from the curves given in Figure 1. At early-prophase. the average grain count over the chromosomes falls down to about 14 percent of that at interphase. No incorporation of uridine was observed in the metaphasic and/or anaphasic chromosomes. The beginning of the incorporation of uridine into the chromosomes was observed at early-telophase when coiling of each chromosome was still retained. An abrupt increase of the incorporation of uridine in the telophasic chromosomes was observed from mid-telophase, presumably owing to catachromasis of each chromosome.

Uptake of $\mathrm{P}^{32} \mathrm{O}_{4}$ and $\mathrm{S}^{35} \mathrm{O}_{4}$ has been studied in several cell types and found to decline during cell division (Taylor and Taylor 1953; Mazia and Prescott 1954;

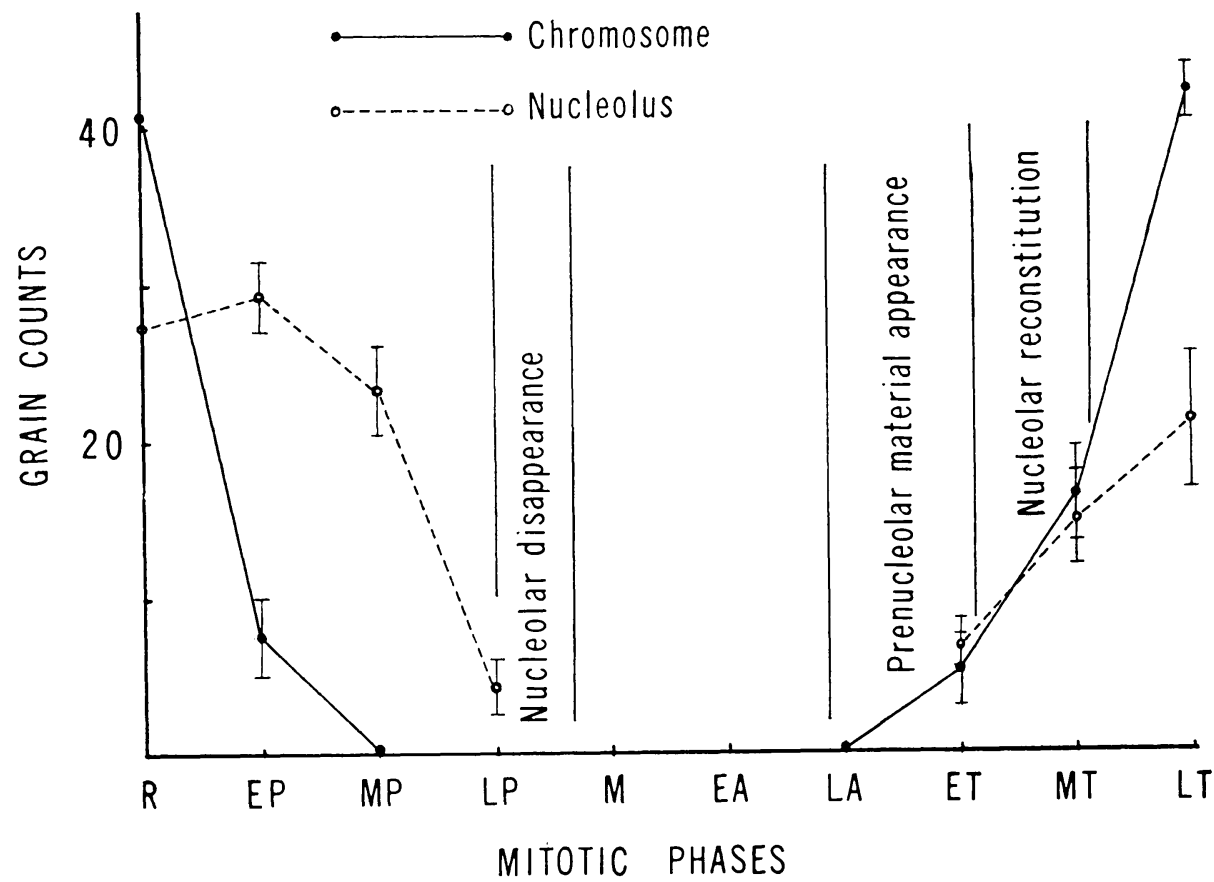

Fig. 1. Average grain counts on chromosome and nucleolus at different stages of the mitotic cycle. Stages: R, interphase; EP, early-prophase; MP, midprophase; LP, late-prophase, $\cdot M$, metaphase ; EA, early-anaphase; I.A, lateanaphase; ET, early-telophase; MT, mid-telophase; LT, late-telophase. Ana-Telophase counts are the sum of counts over chromosomal groups. 
Taylor 1958). Many investigations have recently been directed toward the uptake of specific precursors for RNA, DNA and proteins during cell cycle (Siskin 1959; Taylor 1958; Taylor 1959). The results obtained indicate that mitosis is a period specified with a depressed metabolic activity. Taylor (1960) and Prescott and Bender (1962) suggest that RNA synthesis compeletly stops when the chromosomes are condensed in mitosis. It is supposed that the DNA of condensed mitotic chromosomes seems to be masked in such a way as to lower its ability to prime RNA synthesis, e. g., the DNA-dependent RNA polymerase may not be able to bind to the DNA (Konrad 1963).

In nucleoli, there is a slight increase of incorporation (3.6 percent) of uridine at early-prophase as compared with the average grain count in interphase. The incorporation of uridine slightly declines in mid-prophase (13.7 percent), and remarkably declines by the stage close to late-prophase, i. e., immediately before the disappearance of nucleoli. Prescott and Bender (1962) have demonstrated that the RNA synthesis completely ceases in prophase shortly before the disappearance of nucleoli. So far as RNA synthesis in prophase is concerned, the present study strongly supports the Prescott and Bender's opinion. The process of nucleolar disappearance was similar to that observed in meiosis of the plants in the genus Luzula (Brown 1953; Kusanagi 1963).

RNA synthesis appears to resume very rapidly from early-telophase to latetelophase. However, non-radioactive pre-nucleolar material appears associated intimately with the surface of each chromosome already in late-anaphase to earlytelophase. The accumulation of non-radioactive pre-nucleolar material has continued till mid-telophase, and seems to form the nucleoli, giving an impression that the prenucleolar material contains RNA which is synthesized before the stop of RNA synthesis at prophase. The completion of nucleolar formation in daughter nuclei is observed from early-telophase to mid-telophase, even before the cells pass to typical interphase.

Recent autoradiographic and microphotometric studies suggest that a resumption of both synthetic activity of RNA and of protein occurs within telophase nuclei (Woodard, Rasch and Swift 1959; Prescott and Bender 1962; Das 1963). According to Prescott and Bender (1962), this synthetic activity is already well under way before the nucleolus become visible in the telophase nucleus. Moreover, Lafontene and Chouinard (1963) also suggest from their electronmicroscopic study that the pre-nucleolar material including RNA and proteins comes from the resumed synthesis in the telophase chromosomes. In these findings it seems not unreasonable to conceive that the prenucleolar material is produced mostly by synthetic activity of early-and mid-telophase chromosomes. In the present study, it is clear that RNA of the pre-nucleolar material is already present before RNA synthesis in telophase, as shown by Errera and Brunfaut (1964). This evidence seems to support the view that the pre-nucleolar material is derived from a preexisting matrical substance by mere shedding. Recently, the pre- 
sent author (unpublished) has observed that nucleolar material, especially the nucleolar RNA or RNA containing component, moves to chromosomes in late-prophase, and then, being associated with chromosomes, enters into daughter nuclei. The remaining RNA disperses in or around the spindle body as well as in cytoplasm. Some of the dispersed RNA reassembles in daughter nucleoli when mitosis is completed. In the present study, it is observed that the nucleolus develops along with the increase of the incorporation of uridine into chromosomes and nucleolus itself.

Our data, therefore, seem to indicate that there are two sorts of nucleolar material in newly formed nucleoli, i. e, the one preexisting in or around the chromosomes and in spindle or cytoplasm and the other one newly synthesized by the resumption of synthetic activity of the early- and mid-telophase chromosomes.

Table 1. Results of whole nuclear grain counts over root cells of Luzula purpurea exposed to uridine- $\mathrm{H}^{3}$ for 10 minutes

\begin{tabular}{lccc}
\hline & & \multicolumn{2}{c}{ Mean number of grains } \\
\cline { 3 - 4 } Nuclear stages & Nuclei (No.) & Chromatin & Nucleolus \\
\hline Interphase & 105 & $40.2 \pm 3.8$ & $27.5 \pm 1.0$ \\
Early-prophase & 83 & $7.5 \pm 2.3$ & $29.6 \pm 2.0$ \\
Mid-prophase & 60 & 0 & $23.3 \pm 2.4$ \\
Late-prophase & 54 & 0 & $4.1 \pm 1.5$ \\
Metaphase & 101 & 0 & 0 \\
Early-anaphase & 42 & 0 & 0 \\
Late-anaphase & 47 & 0 & 0 \\
Early-telophase & 31 & $5.2 \pm 2.0$ & $6.4 \pm 1.3$ \\
Mid-telophase & 25 & $18.0 \pm 3.2$ & $15.1 \pm 3.0$ \\
Late-telophase & 73 & $41.7 \pm 1.5$ & $21.3 \pm 4.3$ \\
\hline
\end{tabular}

\section{SUMMARY}

RNA synthesis during mitosis was studied by autoradiographic techniques in the root meristematic cells of Luzula purpurea $(\mathrm{n}=3)$.

Comparisons of the synthetic activity of the interphase with those of other mitotic phases were made using whole nuclear grain counts.

Incorporation of uridine- $\mathrm{H}^{3}$ in chromosomes decreased during early-prophase and completely stopped at mid-prophase. Incorporation of uridine- $\mathrm{H}^{3}$ in nucleoli was retained until late-prophase, just before nucleolar disintegration. No incorporation of uridine- $\mathrm{H}^{3}$ was observed in meta-anaphase chromosomes. Incorporation of uridine- $\mathrm{H}^{3}$ into the daughter chromosomal groups began at early-telophase and continued until late-telophase.

Pre-nucleolar material appeared on the surface of each chromosome as early as in late-anaphase before RNA synthesis resumed in daughter nuclei. Nucleolus developed 
in parallel with an increase of the incorporation of uridine $-\mathrm{H}^{3}$ in chromosomes and nucleolus itself.

\section{ACKNOWLEDGEMENT}

The author wishes to express his sincere thanks to Prof. Nobunori Tanaka of University of Tokyo for his continuous stimulation and instructive suggestions during this work. This work was supported by a Grant in Aid Scientific Research of Ministry of Education (95212).

\section{LITERATURE CITED}

Brown, S. W., 1953 Mitosis and meiosis in Luzula campestris. D. C. Univ. Calif. Publ. Bot. 27 : 231-278.

Conger, A. D., and L. M. Fairchild, 1953 A quick-freeze method for making smear slides permanent. Stain Tech. $28: 281$.

Das, N., 1963 Chromosomal and nucleolar RNA synthesis in root tips during mitosis. Science 140: 1231-1233.

Errera, M., and M. Brunfaut, 1964 Observations of mitotic figures in pulse labeled HeLa cells. Exp. Cell Res. 33: 105-111.

Konrad, C. G., 1963 Protein synthesis and RNA synthesis during mitosis in animal cells. J. Cell Biol. 19: 267-277.

Kusanagi, A., 1963 The nucleolar breakdown observed in meiosis of Luzula species. CIS 3: 13-14.

Lafontene, J. G., and L. A. Chouinard, 1963 A correlated light and electron microscope study of the nucleolar material during mitosis in Vicia faba. J. Cell Biol. 17: 167-201.

Malheiros, S. N., D. Castro, and A. Camara, 1947 Cromosomas sem centromero localizado. O caso da Luzula purpurea Link. Agronomia Lusitana 9: 51-74.

Mazia, D., and D. M. Prescott, 1954 Nuclear function and mitosis. Science 120: 120-122.

Prescott, D. M., and A.M. Bender, 1962 Synthesis of RNA and protein during mitosis in mammalian tissue culture cells. Exp. Cell Res. 26: 260-268.

Siskin, J.E., 1959 The synthesis of nucleic acids and proteins in the nuclei of Tradescantia root tips. Exp. Cell Res. 16: 602-614.

Taylor, J.H., 1958 Incorporation of phosphorus-32 into nucleic acids and proteins during microgametogenesis of Tulbaghia. Am. J. Bot. 45: 123-131.

Taylor, J.H., 1959 Autoradiographic studies of nucleic acids and proteins during meiosis in Lilium longiflorum. Am. J. Bot. 46: 477-484.

Taylor, J. H., and S. H. Taylor, 1953 The autoradiograph-a tool for cytogenetics. J. Heredity 44: 129-132.

Woodard, J., E. Rasch, and H. Swift, 1961 Nucleic acid and protein metabolism during the mitotic cycle in Vicia faba. J. Biophys. Biochem. Cytol. 9: 445-462. 